\title{
AS TRIBUTAC̣ÕES AUTÓNOMAS E A DUPLA TRIBUTAC̣ÃO DAS EMPRESAS. BREVE REFLEXÃO SOBRE AS INCOERÊNCIAS DO SISTEMA FISCAL PORTUGUÊS
}

\author{
DOMINGOS PEREIRA DE SOUSA \\ PROFESSOR CATEDRÁTICO DA FACULDADE DE DIREITO DA \\ UNIVERSIDADE LUSÓFONA DE LISBOA
}

\begin{abstract}
The Portuguese tax system presents inconsistencies and contradictions that put the constitutional principles of tax justice and ethics in the relations between the State and taxpayers in crisis. By constitutional imperative, the taxable profit must be equal to the taxable profit, calculated in the accounting, it is anomalous that the law considers certain expenses demonstrably borne by the companies, however, they are not deductible for the purpose of calculating the taxable profit. Payments on account and autonomous taxation generate tax payments even when there is no real profit, and increased taxation in cases where the company has a loss, which violates the principles of tax justice, in particular the principle of contributory capacity, while foundation and limit of the power to tax.
\end{abstract}

KEYWORDS: tax law, tax, Portuguese tax system

RESUMO: $\bigcirc$ sistema fiscal português apresenta incongruências e contradições que põem em crise os princípios constitucionais da justiça fiscal e a ética nas relações entre o Estado e os contribuintes. Por imperativo constitucional, o lucro tributável deve ser igual ao lucro real, apurado na contabilidade, resulta anómalo que a lei considere certos gastos comprovadamente suportados pelas empresas, todavia, não são dedutíveis para efeito do cálculo do lucro tributável. Os pagamentos por conta e as tributações autónomas geram pagamentos de imposto mesmo quando não se apura lucro real, e tributação agravada nos casos em que a empresa tem prejuízo, o que viola os princípios da justiça tributária, em especial o princípio da capacidade contributiva, enquanto fundamento e limite do poder de tributar.

KEYWORDS: direito tributário, direito fiscal, sistema fiscal português

SUMÁRIO: 1) $\bigcirc$ imperativo constitucional da justa tributação dos rendimentos. 2) $\bigcirc$ princípio ético da capacidade contributiva e as presunções legais. 3) A legitimação constitucional e a predeterminação legal. 4) A tributação do lucro real das empresas. 5) $\bigcirc$ balanço como instrumento de gestão. 6) As tributações autónomas. 7) Origem das tributações autónomas. 8) Natureza e âmbito das tributações autónomas. 9) As tributações avulsas. 10) Impacto das tributações autónomas.

\section{O imperativo constitucional da justa tributação dos rendimentos}

Nos termos da Constituição portuguesa, o imposto sobre o rendimento pessoal deve ser único e progressivo e a tributação das empresas deve ser feita, predominantemente, pelo rendimento real (art. 104. ${ }^{\circ}$ n. ${ }^{\circ}$ s 1 e 2, da CRP). Existe um imperativo constitucional dirigido ao legislador fiscal - este, ao que parece, cada vez mais se vai afastando de tal determinação - de procurar uma tributação justa dos rendimentos, que seja capaz de contribuir para a diminuição das desigualdades na repartição da riqueza e dos rendimentos e, simultaneamente, permita viabilizar o investimento necessário à criação de emprego e ao crescimento económico. Na configuração inicial do sistema, aquando da reforma fiscal dos anos oitenta ${ }^{1}$ o legislador do Imposto Sobre o Rendimento das Pessoas Singulares (IRS) justificou a solução do tratamento unitário do rendimento pessoal sujeito à progressividade. Para tanto, invocou que "só a perspectiva unitária permite a distribuição da carga fiscal segundo um esquema racional de progressividade, em consonância com a capacidade contributiva". E fez ainda questão de sublinhar que essa era a solução que então se impunha "em nome da necessidade de, por via do sistema fiscal, se corrigir a distribuição primária do rendimento que decorre do processo produtivo, de modo a operar uma redistribuição secundária que concorra para definir um padrão de distribuição tido como social e politicamente mais aceitável". 
DOI: 10.46294/ulplr-rdulp.siv 1 a5

Não obstante, o legislador logo acabaria por adotar dois tipos diferentes de imposto: um IRS normal, claramente progressivo, para os rendimentos de trabalho e pensões, sujeitos a englobamento e às taxas normais e progressivas (art. 68. do CIRS), e um outro IRS, anormal, para os rendimentos de capitais em que a tributação se processa por retenção na fonte com taxas proporcionais, liberatórias e especiais (art. 71. e $72 .^{\circ}$ do CIRS).

Os vícios e contradições de que enferma o sistema fiscal português manifestamse, desde o seu início, e estão logo presentes na definição do modelo, em que - legislador fez a opção de compatibilizar a tributação unitária e progressiva dos rendimentos pessoais com a necessidade de evitar a fuga dos capitais. Transitoriamente, a solução legislativa foi de compromisso precário, mas em contradição com o imperativo constitucional da progressividade na tributação do rendimento pessoal. $\bigcirc$ mal estava feito e, como é habitual entre nós, o transitório ficou em definitivo, como marca distintiva de um sistema complexo e contraditório, que não se adequa às necessidades de desenvolvimento sustentado.

O sistema fiscal carece de ser revisto para ganhar coerência, clareza, simplicidade e praticabilidade nas suas normas e procedimentos, atributos indispensáveis à certeza do direito e à protecção da confiança dos contribuintes.

No que respeita à tributação das empresas, o legislador fez um esforço objectivo de respeitar a Constituição, tendo consagrado o princípio da tributação do rendimento real das empresas com base no lucro apurado no balanço contabilístico, como claramente resulta na versão originária do Código do Imposto Sobre o Rendimento das Pessoas Colectivas (IRC). Não obstante, o respeito pelos princípios constitucionais, o legislador foi cedendo o passo a alterações casuísticas, quase sempre ditadas pela necessidade de arrecadação de mais receita para financiar a excessiva despesa corrente do Estado social.

\section{O princípio ético da capacidade contributiva e as presunções legais}

Em sede de teoria geral dos impostos, é hoje doutrina assente que a tributação do rendimento pessoal deve ter na capacidade contributiva o critério e a medida da igualdade tributária. Nesse sentido, a legitimidade do imposto depara com a limitação que resulta da existência efectiva de capacidade económica, seja ela manifestada pela obtenção de um rendimento líquido Iganho, renda, lucro, maisvalia), pela propriedade ou usufruição de um certo bem patrimonial ou, ainda, pela capacidade revelada através de um acto de aquisição para consumo.

Toda e qualquer manifestação do poder tributário tem de incidir sobre uma manifestação de riqueza efectiva (real e não presumida) e actual ${ }^{2}$. A capacidade contributiva é o único fundamento e o limite desse poder de tributar.

$\bigcirc$ princípio da capacidade contributiva é, em definitivo, um princípio ético e estruturante do sistema fiscal que se impõe ao legislador pela sua natureza supraconstitucional. Enquanto princípio estruturante orienta o legislador na definição da medida da igualdade do sacrifício fiscal a exigir aos contribuintes. Por outras palavras, a capacidade contributiva é o princípio orientador da medida da desutilidade económica a impor a cada um dos contribuintes que reúnam os pressupostos da norma de incidência tributária, tendo em vista uma igualdade material na lei ${ }^{3}$.

A igualdade tributária constitui hoje uma expressão específica do princípio geral da igualdade, o qual se traduz não apenas na exigência de igualdade formal perante a lei, dirigida à Administração e aos Tribunais, mas também e acima de tudo, em igualdade material na lei, a qual obriga o próprio legislador em termos negativos e em termos positivos. É precisamente esta ideia de igualdade material que obriga o legislador a tratar de forma igual o que é idêntico e a tratar desigualmente o que é diferente.

p primeiro aspecto da igualdade tributária manifesta-se na generalidade ou universalidade do imposto, no sentido de não discriminação. Da generalidade tributária decorre que todos os cidadãos, sem distinção de espécie alguma, têm o dever de pagar impostos. Desse dever ninguém pode ser excluído, e todos devem pagar impostos por todas as manifestações de capacidade económica que o legislador define como reveladoras de capacidade de contribuir para o financiamento dos gastos públicos ${ }^{4}$

A capacidade contributiva deve ser entendida como capacidade de pagar, conceito este que é bem mais amplo do que o de capacidade económica, uma

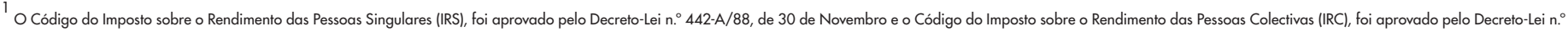
442-B/88, de 30 de Novembro, ambos no uso da autorização legislativa concedida pela Lei no 106/88, de 17 de Setembro.

2 A

A retroatividade dos impostos está constitucionalmente vedada (art. 103. ${ }^{\circ},{ }^{\circ} 3$ da CRP).

3 Para um estudo mais desenvolvido sobre os princípios constitucionais da justiça tributária, ver Domingos Pereira de Sousa, Direito Fiscal e Processo Tributário, (Coimbra: Coimbra Editora, 2013), pp. 79-117.

${ }^{4}$ Neste sentido, P. Yebra Martul-Ortega, La Justicia Fiscal y el Impuesto sobre la Renta, (Universidad de Santiago de Compostela, 1973), p. 51 e ss. 
vez que, para além de atender aos índices objectivos /rendimento, património e consumol que servem de critérios de medida da capacidade económica, a capacidade contributiva tem, ainda, por base índices pessoais ou subjectivos. $\bigcirc$ princípio da capacidade contributiva remete-nos para uma igualdade tributária, em termos aritméticos, também designada de «igualdade no imposto», da qual resulta a exigência de impostos iguais para capacidades económicas idênticas e impostos desiguais para capacidades diversas, na proporção da diferença.

Todos têm o dever de contribuir de acordo com a respectiva capacidade contributiva e em nome da justiça devem ser tributadas todas as manifestações de capacidade económica, evitando-se a fraude e a evasão fiscal. Por isso, insistimos na necessidade de a Administração estar habilitada com os poderes e instrumentos jurídicos necessários e adequados para a realização do fim de interesse público que constitui o imperativo constitucional de uma justiça fiscal assente no dever geral de contribuir para a cobertura dos encargos financeiros do Estado.

Em conclusão do que vem de ser dito, a capacidade contributiva deve ser considerada como princípio fundamental material de uma tributação socialmente justa, elevado à condição de pressuposto, critério e medida da tributação ${ }^{5}$. Enquanto pressuposto de uma tributação materialmente justa, o princípio da capacidade contributiva implica, desde logo, a isenção das pessoas que não possuem capacidade para pagar impostos e a necessidade de o legislador definir um mínimo de existência fiscal e proceder à consequente exclusão desse montante do campo de incidência tributária. No essencial, a capacidade contributiva é um princípio de ética nas relações entre o Estado e os cidadãos contribuintes.

A esta luz, não é recomendável que no domínio dos elementos essenciais da relação jurídica tributária (incidência, taxa, benefícios fiscais, garantias dos contribuintes) submetidos a uma exigência de tipificação legal por força do princípio da legalidade (art. 103. ${ }^{\circ}$, n. 2 , da CRP), o legislador faça uso frequente de normas abertas e elásticas que concedem espaço à subjectividade, como ocorre nos casos em que admite a quantificação da incidência do imposto por avaliação indirecta, com base em presunções de existência de factos tributários ${ }^{6}$. São vários os exemplos que podem ser avançados no sistema fiscal português.
Em sede de IRS e no que respeita aos rendimentos de capitais (categoria E), - legislador consagra a presunção da existência de rendimentos de capital nos contratos de mútuo e nos lançamentos feitos a crédito nas contas correntes dos sócios das sociedades, os quais se presumem feitos a título de lucros ou adiantamento dos lucros (art. 6.', n. ${ }^{\circ}$ s 1, 2, 4, do CIRS).

Resultando de presunções, todos esses factos tributários carecem de ser provados materialmente pela Autoridade Tributária e Aduaneira, sob pena de eventual declaração judicial de ilegalidade do procedimento de liquidação. Com efeito, todas as presunções consagradas nas normas de incidência tributária são ilidíveis, pelo que admitem sempre prova em contrário (art. 73. da LGT) e "podem ser ilididas com base em decisão judicial, acto administrativo, declaração do Banco de Portugal ou reconhecimento pela Autoridade Tributária e Aduaneira" lart. 6. , n. 5 , do CIRS).

\section{A legitimação constitucional e a predeterminação legal}

A definição em abstrato na lei fiscal do que deve ser considerado gasto é problema de legitimação, isto é, o legislador fiscal deve respeitar os princípios constitucionais da justiça fiscal.

Um dos problemas mais significativos que aí se levantam prendem-se com a complexidade das normas fiscais resultante da indeterminação imanente de alguns conceitos que se contêm em boa parte das regras contabilísticas, indeterminação que não desaparece, antes se agrava, quando o legislador fiscal confere uma formulação específica a tais conceitos ${ }^{7}$. Se é certo que, regra geral, a lei fiscal faz um uso normal dos conceitos legais, acontece que, por vezes, o legislador fiscal procede a adaptações de alguns conceitos jurídicos, conferindo-thes conteúdo diverso daquele que assumem noutros ramos do direito, o que chega a configurar autênticas derrogações de normas constantes, quer da legislação comercial, quer da legislação da contabilidade.

Admitimos que o legislador necessita de margem de liberdade de conformação para definir os gastos fiscalmente relevantes. Mas, sempre que o legislador

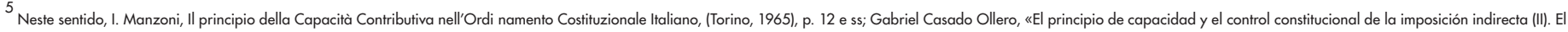
contenido constitucional de la capacidad económica», Civitas. Revista Española de Derecho Financeiro, n. ${ }^{\circ} 34$, (1982), p. 190 e ss. ${ }^{2}$ A retroatividade dos impostos está constitucionalmente vedada (art. 103. ${ }^{\circ} .3$ da CRP).

${ }^{6}$ A avaliação indirecta visa a determinação do valor dos rendimentos ou bens tributáveis a partir de indícios, presunções ou outros elementos de que a administração tributária disponha (art. 83. ${ }^{\circ}$ da LGT).

7 J. L. Saldanha Sanches. Manual de Direito Fiscal, (Coimbra: Coimbra Editora, 2002), pp. 268-270.
} 
DOI: 10.46294/ulplr-rdulp.siv la5

adultera conceitos já firmados noutros ramos de direito, tais opções carecem de ser amplamente justificadas e sempre em respeito pelo equilíbrio entre os princípios constitucionais, os quais constituem o fundamento e o limite da própria legitimidade do legislador fiscal.

Nessa perspectiva, é razoável que o legislador estabeleça que as coimas pagas pela empresa não são consideradas gastos fiscais, já que a medida da sanção surge como forma de eliminar a vantagem que resultaria de um comportamento ilícito. Mas, já não é razoável que os juros compensatórios suportados pela empresa não sejam considerados gastos, uma vez que tais juros não têm natureza sancionatória.

A questão de saber quais as despesas a considerar no apuramento do rendimento líquido tem um forte impacto na tributação das empresas. Do nosso ponto de vista, a distinção tem de ser feita entre despesas que têm uma finalidade empresarial e as despesas que têm uma estrita finalidade pessoal, considerando sempre dedutíveis como gastos empresariais aquelas despesas que sejam necessárias ao desenvolvimento da actividade e à produção do rendimento, isto é, despesas que estão em indiscutível conexão objetiva com os fins empresariais ${ }^{8}$.

Nesse sentido, consideramos anómalo que o legislador tenha aditado o artigo 23. -A do CIRC, para enumerar como "encargos não dedutíveis para efeitos fiscais" certos gastos que tendo sido efectiva e comprovadamente suportados pelas empresas, todavia, não podem ser levados em conta para efeito do cálculo do lucro tributável. Ou seja, temos um gasto comprovado que influencia o cálculo do lucro, mas que não pode ser objecto de dedução para efeitos fiscais. Uma vez que o lucro tributável deve ser igual ao lucro real até por imposição constitucional, parece que deparamos com mais uma contradição e uma negação potencial deste princípio.

No plano do procedimento tributário, as correções administrativas à declaração do sujeito passivo justificam-se quando se trate de verdadeiras correções técnicas a certas qualificações ou quantificações feitas pelo sujeito passivo. Pode aceitar-se que a correcção administrativa desconsidere um determinado gasto ou altere o valor de uma determinada despesa, respeitando e mantendo inalterada a estrutura inicial do balanço. A não-aceitação de "gastos comprovados" tem sempre uma natureza excecional e deverá ser legitimada, nomeadamente, pelo carácter sancionatório da medida.

Como estamos perante um fenómeno de massas, é desejável que o legislador evite cair no exagero de tudo tipificar, tolhendo a Administração e amarrando os contribuintes a uma legalidade formal estrita e ultrapassada. A solução em termos de praticabilidade das leis e o normal funcionamento da administração tributária exige a predeterminação legal de um conjunto de critérios objectivos em matéria de apuramento do lucro, que dê garantias de um controlo racional e eficiente dos milhares de declarações de pequenas e médias empresas. Ou seja, a solução passa pela normalização, na base de tabelas e de quotas-padrão, e pela identificação e tipificação taxativa dos casos excecionais conhecidos de desvio ao padrão, como é o caso de certas amortizações especiais e de algumas provisões ${ }^{9}$. Fora destes casos, a rigidez da predeterminação legal tem de ser compensada com a previsão de procedimentos de avaliação para casos especiais que escapam aos critérios gerais previstos na lei.

Do nosso ponto de vista, estes procedimentos devem caminhar no sentido de aprofundar os mecanismos de autonomia da Administração e dos contribuintes, criando espaços para a negociação na quantificação destes elementos da base tributária.

\section{A tributação do lucro real das empresas}

A Constituição da República Portuguesa determina no seu artigo 104. ${ }^{\circ}$, n. 2 que "a tributação das empresas incide fundamentalmente sobre o seu rendimento real», expressando em termos precisos uma clara opção pelo princípio da tributação dos rendimentos reais das empresas, no sentido de que só deve ser tributado o rendimento real e só este ${ }^{10}$.

A Constituição consagra, assim, expressamente, o direito dos contribuintes (empresas e profissionais independentes) de serem tributados com base exclusiva na sua contabilidade. Como é natural, a contabilidade, enquanto instrumento de informação e avaliação da empresa deve ser o espelho que reflete a vida da empresa, no sentido em que retrata com transparência todas as operações realizadas $^{11}$.

De resto, o princípio do rendimento real acaba por ser uma forma de concretização

8 Devem ser considerados todos os gastos indispensáveis à realização do lucro, tal como estabelece o artigo 23. o do CIRC.

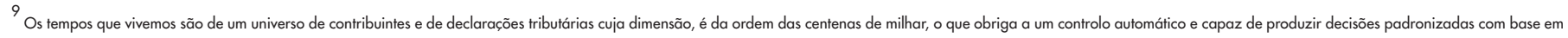
algoritmos predefinidos.

${ }^{10}$ Nesse sentido, Diogo Leite de Campos e Mônica Horta Neves Leite de Campos. Direito Tributário, (Coimbra: Almedina, 2003), pp. 127-129.

${ }^{11}$ Nesse sentido, Domingos Pereira de Sousa, Direito Fiscal e Processo Tributário, p. 482 e ss; J. L. Saldanha Sanches. Manual de Direito Fiscal, p. 272. 
dos princípios da capacidade contributiva e da igualdade fiscal ${ }^{12}$. O legislador constituinte reafirmou assim a sua clara opção pela tributação dos rendimentos reais em detrimento da tributação dos rendimentos normais. Mas, uma vez mais, a solução adoptada foi de compromisso, já que o legislador afirma o carácter "fundamentalmente" real da tributação do rendimento das empresas, o que não implica exclusividade, nem impede a tributação de rendimentos normais. Por isso, alguns autores manifestaram dúvidas sérias e pertinentes relativamente ao sistema de tributação das empresas em Portugal. Em bom rigor, a imposição constitucional da tributação das empresas de acordo com o princípio do rendimento real não exclui liminarmente toda e qualquer possibilidade de recurso à tributação baseada em rendimentos normais, designadamente em relação aos pequenos contribuintes e às empresas com elevado potencial de evasão fiscal ${ }^{13}$.

Na verdade, as soluções adoptadas para prevenir a evasão fiscal têm resultado, na prática, em injustiças muitas vezes causadas pela tributação de rendimentos supostamente reais e que na maior parte dos casos resultam de valores fictícios. Este fenómeno tende a agravar as desigualdades na distribuição da riqueza e dos rendimentos com vantagens injustificadas em especial ao nível das grandes empresas que têm maiores possibilidades para "rodearem de ficções" a realidade dos seus rendimentos, em detrimento dos pequenos e médios contribuintes. As desigualdades são notórias quando, pela sua dimensão e volume de negócios, algumas empresas multinacionais se podem dar ao luxo de escolher o regime fiscal mais conveniente, deslocalizando a respectiva sede social em busca de isenções e outras vantagens fiscais que resultam quase sempre em não tributação de lucros generosos $^{14}$.

A necessidade de delimitar o período temporal sujeito a tributação determina a consagração do princípio da especialização dos exercícios, assim fazendo corresponder o lucro tributável ao lucro real, isto é, ao lucro efectivamente realizado durante o período, em regra anual, da actividade económica empresarial ${ }^{15}$. Tratase de tributar um lucro efectivamente alcançado, isto é, um resultado positivo e minimamente "consolidado" do exercício económico, enquanto manifestação concreta - realizada e não meramente realizável ou potencial - de capacidade contributiva.

Na generalidade dos países desenvolvidos, o lucro das empresas é determinado de forma real, tendo por única base a contabilidade organizada. A avaliação por presunção da matéria coletável tem natureza excepcional. O lucro tributável das empresas tem por base o lucro apurado no balanço, por aplicação dos princípios e regras da contabilidade, constantes do Sistema de Normalização Contabilística $(\mathrm{SNC})^{16}$. Contudo, não existe uma correspondência total entre o lucro tributável e - lucro contabilístico, uma vez que o lucro líquido está sujeito a correcções fiscais ${ }^{17}$. A ideia de lucro líquido do exercício da teoria do balanço é refirmada no n. 1 do artigo 17. do CIRC quando estabelece que o lucro tributável das empresas é constituído pela soma algébrica do resultado líquido do período e das variações patrimoniais positivas e negativas, determinados com base na contabilidade.

\section{O balanço como instrumento de gestão}

As empresas estão legalmente obrigadas à prestação de contas, sendo fundamental que as contas anuais proporcionem uma imagem fiel da situação patrimonial da empresa $^{18}$.

O balanço comercial funciona como instrumento de gestão empresarial; descreve e reflete a situação patrimonial da empresa; é a base de cálculo económico do seu lucro ou prejuízo; serve de referência para a definição dos direitos dos sócios e das relações com terceiros (credores e devedores). O balanço fiscal corresponde ao balanço comercial corrigido de acordo com as normas fiscais e nesse sentido serve de instrumento de quantificação do imposto.

Resulta, assim, que as empresas são obrigadas a ter contabilidade organizada nos termos da lei comercial e fiscal, de forma a permitir o controlo do lucro tributável ${ }^{19}$. Por isso, a contabilidade deve estar organizada em conformidade com as normas

${ }^{12}$ Nesse sentido, José Casalta Nabais, Direito Fiscal, 7. ed., (Coimbra: Almedina, 2012), p. 174.

${ }^{13}$ Nesse sentido, J. J. Teixeira Ribeiro, Lições de Finanças Públicas. 5. ${ }^{a}$ ed., (Coimbra: Coimbra Editora, 1995), p. 307.

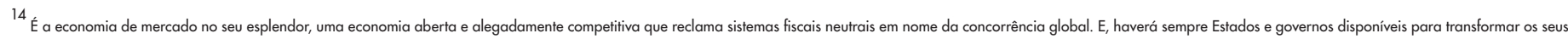
territórios em autênticos paraísos fiscais. E sempre que as decisões de política económica são confrontadas com a manifesta violação da equidade fiscal, logo surgem as justificações suportadas na oportunidade da atracção do investimento, no crescimento económico e na criação de emprego.

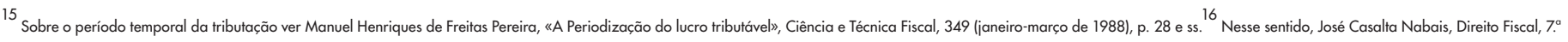
ed., (Coimbra: Almedina, 2012), p. 174.

${ }^{16}$ Aprovado pelo Decreto-Lei n. ${ }^{158 / 2009}$, de 13 de julho.

17 Como resulta do artigo $3 .{ }^{\circ}, \mathrm{n} .{ }^{\circ}$ 2, do CIRC, que estabelece que "o lucro consiste na diferença entre os valores do património líquido no fim e no início do período de tributação, com as correcções estabelecidas neste Código".

${ }^{18}$ Artigos $65^{\circ}$ a $70 .^{\circ}$ do Código das Sociedades Comerciais, aprovado pelo Decreto-Lei n. $262 / 86$, de 2 de setembro e artigo 3. ${ }^{\circ}$ alínea n), do Código do Registo Comercial, aprovado pelo Decreto-Lei n. $403 / 86$, de 3 de dezembro. 
DOI: 10.46294/ulplr-rdulp.siv la5

internacionais de contabilidade (NIC), tal como adoptadas pela União Europeia ${ }^{20}$. Na maior parte das legislações fiscais o lucro coletável das empresas é determinado a partir da teoria do balanço, segundo a qual o lucro fiscal é igual à variação do ativo líquido da sociedade no decurso do período da tributação, no sentido de um lucro realizado, o que implica que a tributação incide sobre um resultado líquido (o lucro de exploração) corrigido dos eventuais ganhos e perdas nos ativos da empresa. Ao resultado do exercício são adicionados as receitas acessórias e os ganhos de capital ou mais-valias e subtraídas as despesas gerais com encargos, perdas, amortizações e provisões.

De acordo com a teoria do balanço, o rendimento tributável resulta da comparação dos balanços no princípio e no fim do período da tributação, circunstância que autoriza a tributação de todos os ganhos, independentemente da origem e natureza, realizados pela empresa no período considerado ${ }^{21}$.

Com a teoria do balanço, o legislador fiscal português consagrou a teoria do acréscimo ou do incremento patrimonial, em que o lucro tributável é reportado à diferença entre o património líquido no início e no fim do período de tributação. Assim, o lucro tributável reporta ao resultado líquido do exercício constante da demonstração de resultados líquidos, a que acrescem as variações patrimoniais positivas e negativas verificadas no mesmo período e não refletidas naquele resultado.

período de tributação, em princípio, é de um ano e coincide com o ano civil $^{23}$, sem prejuízo da adopção do mecanismo de reporte dos prejúżos como instrumento de salvaguarda da solidariedade dos exercícios. A continuidade da empresa como unidade económica não pode ser posta em crise pela segmentação temporal do rendimento ${ }^{24}$.

O direito ao balanço é a garantia de uma tributação pelo rendimento líquido e objectivo (contabilístico), no respeito pelo princípio da especialização dos exercícios, o qual exige a delimitação do período temporal a que respeitam os rendimentos e gastos. $\bigcirc$ direito a ser tributado com base no balanço comercial constitui um verdadeiro direito subjectivo que não pode sofrer restrições excessivas ${ }^{25}$. As medidas restritivas estão sujeitas ao princípio da proporcionalidade, no sentido de que devem ser adequadas, isto é, equilibradas e não excessivas.

Do que vem de ser dito, parece não restar margem para dúvidas de que tributar - rendimento real das empresas significa atingir a matéria coletável realmente auferida pelo sujeito passivo ${ }^{26}$. Nos termos da lei, o apuramento da matéria coletável é feito com base na declaração do sujeito passivo ${ }^{27}$, ou seja, o apuramento do lucro tributável das empresas é feito com base no balanço. Esta é a regra geral, sem prejuízo do controlo pela administração fiscal ${ }^{28}$.

Em termos simples, o lucro tributável é igual à diferença positiva entre os valores do património em dois tempos distintos, antes e no fim do período. As amortizações devem reflectir com verdade a perda anual de valor dos bens do activo imobilizado da empresa, por razões económicas e por razões fiscais. Isto, sem levar em conta as mais e menos-valias latentes (ou não realizadas) que, embora presentes no património da empresa, não são consideradas nem no balanço comercial nem no balanço fiscal.

\section{As tributações autónomas}

Em nome de uma suposta eficiência, o legislador de forma avulsa e juridicamente inaceitável, vai introduzindo "esquemas" de tributação que, manifestamente, violam os princípios constitucionais da justiça fiscal e, do mesmo passo, acabam com a "coerência inicial" do sistema fiscal. Tais soluções legislativas avulsas resultam, desde logo, em manifesta violação dos princípios da capacidade contributiva e da tipicidade, princípios estruturantes do sistema fiscal no Estado de Direito.

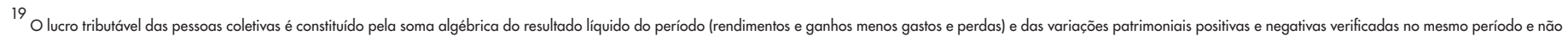
reflectidas naquele resultado, determinados com base na contabilidade e eventualmente corrigidos nos termos do Código (artigo 17\%, n. 1 do CIRC).

${ }^{20}$ O Sistema de Normalização Contabilística (SNC) foi aprovado pelo Decreto-Lei n. ${ }^{\circ}$ 158/2009, de 13 de julho, em sintonia com as normas internacionais de contabilidade (NIC) adoptadas pela União Europeia.

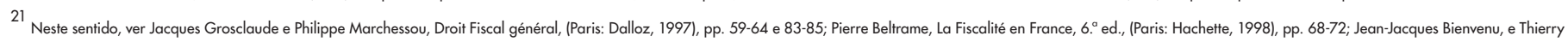
Lambert, Droit Fiscal, (Paris: PUF, 1987), p. 200 e ss; Isabelle de Kerviler, Droit Comptable Entrepises, (Paris: Económica, 1986); Henry Tilbery, Imposto de Renda - Pessoas Jurídicas, in Ives Gandra da Silva Martins (Coord.), Curso de Direito

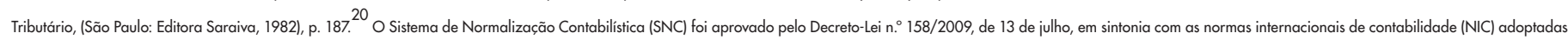
pela União Europeia.

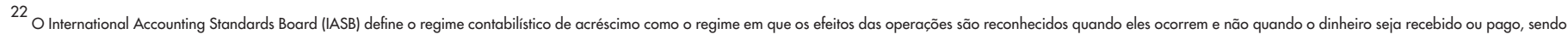
registadas nos livros contabilísticos e relatadas nas demonstrações financeiras dos períodos com os quais se relacionem.

${ }^{23}$ Cfr. artigo $8 .^{\circ}$ do CIRC.

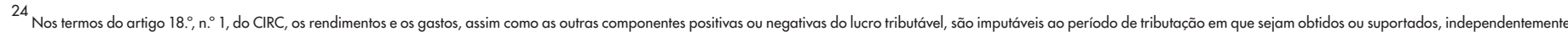

do seu recebimento ou pagamento, de acordo com o regime de periodização económica. Os recebimentos e os pagamentos integram-se na demonstração de resultados dos períodos a que respeitam as respetivas transaçães

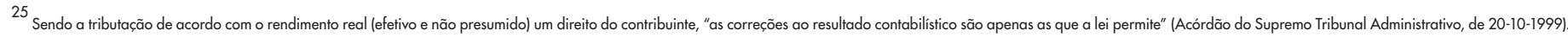


DOI: 10.46294/ulplr-rdulp.siv la5

Com efeito, o legislador fiscal viola de forma grosseira o princípio da tipicidade, ao incluir no plano de incidência do imposto sobre o rendimento factos que nem sequer podem ser considerados valores ou ativos que tenham sido acrescidos ao património, como acontece em todos os casos de tributações autónomas previstas nos artigos $73 .^{\circ}$ do código do IRS e do artigo 88. do código do IRC e em legislação avulsa.

O imposto sobre o rendimento das empresas (IRC), com pagamentos por conta e taxas de tributação autónoma, que geram pagamento de imposto mesmo quando não se apura lucro real, e que determinam mesmo a tributação agravada nos casos em que a empresa tem prejuízo, tem vindo a transformar-se em instrumento de autêntico esbulho legal, revelando uma intolerável expropriação de riqueza que assume contornos de verdadeiro confisco, uma vez mais em manifesto desrespeito dos princípios constitucionais da justiça tributária.

Na verdade, as empresas suportam estes impostos autónomos, independentemente de terem lucro. Mas, pior ainda, se tiverem prejuízo, essas tributações são agravadas para o dobro. Castigo? Sanção? Qual foi o comportamento adotado pela empresa que deva merecer uma tal censura e reação? Uma vez mais tudo se passa com base em presunções legais de ilicitude e culpa no exercício da gestão empresarial. As tributações autónomas interferem, assim, com a autonomia de gestão, resultando em violação dos direitos fundamentais.

Pressionado pela necessidade de mais receitas, o legislador consagra soluções anormais e aberrantes na definição do rendimento tributável em manifesta contradição com os modernos princípios da tributação que foram adoptados na Reforma Fiscal dos anos oitenta e, em particular, com o princípio da capacidade contributiva. Com este tipo de soluções anormais o legislador afasta-se do modelo original e contraria mesmo os princípios estruturantes do sistema fiscal consagrados na Constituição.
No que respeita às empresas e, em particular, às sociedades comerciais, não restam dúvidas de que existem dois impostos sobre o rendimento das pessoas colectivas (IRC). Na verdade, as sociedades suportam, simultânea e cumulativamente, um imposto normal sobre o lucro "corrigido" e um imposto anormal sobre determinadas despesas, iá designado de "IRC paralelo"29.

Investiguemos os aspectos essenciais da origem, da natureza e âmbito destas tributações autónomas, para neles firmarmos algumas conclusões.

\section{Origem das tributações autónomas}

As tributações autónomas surgem em 1990, com o propósito de compensar eventuais evasões fiscais, no que consideramos a escolha pelo legislador do caminho mais fácil e mais eficaz de garantir receita fiscal.

O legislador optou por penalizar certo tipo de despesas avulsas em detrimento da consagração da margem de decisão da sua eventual desconsideração da dedutibilidade como parcela do gasto. $\bigcirc$ legislador partiu da presunção de que algumas despesas, nomeadamente as despesas confidenciais, encobrem rendimentos atribuídos que são fonte de eventuais fugas à tributação.

Com efeito, as designadas taxas de tributação autónoma dos artigos $88^{\circ}$ do CIRC e 73. do CIRS resultam de um propósito inicial de luta contra a evasão e fuga fiscal. Assim, estas tributações autónomas incidiam apenas sobre situações de grande probabilidade de evasão fiscal como ocorre com as despesas confidenciais e não documentadas.

Não obstante essa finalidade inicial, as tributações autónomas têm vindo a alargar a base de incidência, agravando hoje um conjunto muito heterogéneo de despesas. Às despesas não documentadas, o legislador veio acrescentar as despesas de representação, as despesas com veículos ligeiros de passageiros ${ }^{30}$

\footnotetext{
${ }^{26}$ Sobre a tributação do rendimento real em Portugal, ver José Xavier de Basto, «O Princípio da Tributação do Rendimento Real e a Lei Geral Tributária», Fiscalidade 5, (Lisboa: ISG, 2001 ), pp. 5-21.

27 Artigo $17^{\circ}$, do CIRC

28 Artigo $160^{\circ}$, n. $^{\circ}$, do CIRC

${ }^{29}$ Neste sentido, José Casalta Nabais, A Tributação das Empresas pelo Rendimento Real, Boletim de Ciências Económicas, Vol. LXII, (Coimbra: FDUC, 2019), pp. 121-177.

${ }^{30}$ Todavia, «excluindo os veículos movidos exclusivamente a energia elétrica» (Cfr. artigo 73. , n. 2, parte final, do CIRS e artigo 88. , n. 3, do CIRC).

31 Cfr. Artigo 88. , n. 14, do CIRC.

${ }^{32}$ Nesse sentido, José Casalta Nabais, Introdução ao Direito Fiscal das Empresas, (Coimbra: Almedina, 2013), p. 137.

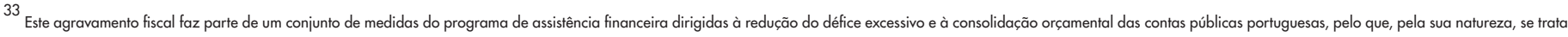
de uma medida fiscal transitória.

34

${ }^{3}$ Cfr. o artigo 18. da Lei n. $73 / 2013$, de 3 de setembro, diploma que estabelece o Regime Financeiro das Autarquias Locais e das Entidades Intermunicipais (RFALEI).

${ }^{35}$ O legislador continua a persistir no erro grosseiro de designar de taxas realidades que são verdadeiros impostos, escapando assim ao controlo da legalidade tributária.
} 
, despesas correspondentes a importâncias pagas a entidades residentes em "paraísos fiscais", despesas relativas a ajudas de custo de trabalhadores, os lucros distribuídos a entidades residentes em paraísos fiscais, os bónus e compensações e outras remunerações variáveis pagas a gestores, administradores ou gerentes. Todas as taxas de tributação autónoma aí previstas que vão desde 5\% a 55\%, de forma injustificada, são elevadas em 10 pontos percentuais em caso de prejuízo fiscal no período a que respeitam os factos tributários ${ }^{31}$

\section{Natureza e âmbito das tributações autónomas}

As tributações autónomas incidem sobre certas despesas, nada têm a ver com a tributação do rendimento real das empresas. Em rigor, elas configuram verdadeiros impostos sobre a despesa, no que constitui uma verdadeira perversão do nosso sistema fiscal.

Trata-se da tributação de certas situações de facto especiais que são tributadas com uma taxa específica, em que no fundo se cria um novo facto tributário que é tratado à margem do lucro tributável e que têm lugar quando certos gastos das empresas são transformados, eles próprios, em factos tributários. As tributações autónomas são, em rigor, verdadeiros impostos sobre a despesa, ainda que apareçam "enxertados" na tributação do rendimento, de forma anómala.

Com efeito, a lei penaliza fortemente as despesas confidenciais ou não documentadas, e que não são consideradas como gastos do período de tributação. A penalização visa evitar comportamentos evasivos e não transparentes que podem encobrir a distribuição oculta de lucros e até o pagamento de outras despesas não documentáveis, eventualmente respeitantes a comportamentos ilícitos. Nessa perspectiva, é aceitável que se mantenha a tributação agravada de certas despesas por motivos de elevada probabilidade de evasão e fraude fiscal. Contudo, não se mostra justificada a sujeição ao mesmo regime de um conjunto de outras despesas que, aparentemente, não constituem sérios riscos de evasão fiscal. Pelo menos, o legislador não apresenta argumentos que fundamentem a sua motivação para a inclusão no mesmo regime de tributação autónoma agravada. As tributações autónomas são verdadeiros impostos sobre a despesa. Tributam de forma agravada despesas que, regra geral, são encargos indispensáveis e conformes com as boas práticas de uma gestão empresarial normal e prudente, que procura ser inovadora e competitiva. As tributações autónomas acrescem à tributação normal que incide sobre o rendimento das empresas, no que acaba por constituir uma injustificada dupla tributação.

Mas, o mais grave e intolerável à luz dos princípios constitucionais da justiça tributária, é que as referidas tributações autónomas ocorrem sempre, mesmo que não haja resultados positivos (lucro) para tributar. E, se a empresa tiver resultados negativos as taxas são agravadas, circunstância que comprova que a única motivação do legislador foi a arrecadação da receita, optando mesmo por penalizar a empresa com prejuízos. Ora, sendo que os resultados da empresa são apurados através do balanço, no primeiro trimestre do ano posterior ao exercício, pode acontecer que à data da realização das despesas, a empresa se encontre numa situação positiva e que, por alteração de circunstâncias, o exercício económico em causa reflectido no balanço termine com resultados negativos. Um tal agravamento baseado nos resultados negativos da empresa é juridicamente intolerável pelo carácter sancionatório que confere a estes verdadeiros impostos sobre a despesa, impostos a que o legislador chamou "tributações autónomas".

Do nosso ponto de vista, estas tributações autónomas configuram uma séria restrição à liberdade económica consagrada constitucionalmente, interferem com a autonomia de gestão normal dos negócios empresariais, colocam sérias dificuldades à competitividade fiscal das nossas empresas. Trata-se de impostos especiais que penalizam gravemente a actividade empresarial, que assim se transforma em "actividade de alto risco" 32 .

planeamento fiscal é um instrumento indispensável na gestão normal das empresas que desenvolvem a sua actividade em mercados globais. Razão bastante para que o legislador nacional oriente a política fiscal por critérios de neutralidade, o que aconselha a que se abandonem todas as medidas de política fiscal que agravam a estrutura de custos de contexto das empresas com sede em território português, em manifesta contradição com a competitividade necessária para enfrentar os desafios da concorrência no mercado global. As tributações autónomas estão, hoje, em contraciclo com os objectivos de crescimento sustentável da economia portuguesa; devem ser abandonadas em definitivo, para que o investimento privado, a criação de emprego e o aumento de rendimentos disponíveis das famílias possam funcionar como efeito acelerador de crescimento e de competitividade. 


\section{As tributações avulsas}

\subsection{A derrama estadual de IRC}

Diferente na natureza jurídica, embora de idêntica finalidade financeira, são as tributações avulsas que vão proliferando no sistema fiscal português.

A derrama estadual sobre o IRC, com uma taxa adicional de $2,5 \%$, que incidia sobre a parte do lucro tributável superior a (euro) 2000 000, foi aditada ao Código do Imposto sobre o Rendimento das Pessoas Colectivas, pela Lei n. 12 A/2010, de 30 de Junho. Esta lei aprova um conjunto de medidas adicionais de consolidação orçamental que visam reforçar e acelerar a redução de défice excessivo e o controlo do crescimento da dívida pública previstos no Programa de Estabilidade e Crescimento (PEC) ${ }^{33}$

Logo aqui temos que esta taxa adicional constitui um agravamento da taxa de IRC, é um autêntico adicionamento ao IRC. Não obstante, a lei designar impropriamente estes impostos acessórios como taxas adicionais, trata-se de verdadeiros adicionamentos, como há muito está assente na doutrina. Com efeito, o adicionamento é um imposto acessório que incide sobre a matéria colectável do imposto principal, enquanto o adicional incide sobre a coleta do imposto principal E isto faz toda a diferença.

Mas, o pior é que este adicionamento foi sofrendo diversas actualizações, e em vez de uma taxa proporcional temos, actualmente, um imposto acessório progressivo, com três escalões, sendo que o primeiro escalão corresponde ao lucro de mais de 1500000 até $7500000 €$, ao qual se aplica a sobretaxa de 3\%, e quando superior a 7500000 e até 35000000 € aplica-se a sobretaxa de 5\% e, por último uma sobretaxa de 9\%, aplicável ao lucro superior a $35000000 €$.

Esta derrama estadual, revela várias incongruências. Desde logo, esta derrama não é um adicional, antes constitui um adicionamento; depois, ao arrepio do imposto principal (IRC) de que depende e que é um imposto proporcional, este adicionamento tem natureza progressiva; acresce que, pela sua natureza, é uma medida fiscal transitória, agora transformada em definitiva; e, por último, a sua progressividade está em manifesta contradição com a natureza proporcional da derrama municipal que os municípios podem lançar, em cada ano, até ao limite máximo de 1,5\%, sobre o lucro tributável sujeito a $\mathrm{IRC}^{34}$.

\subsection{A taxa adicional de solidariedade do IRS}

Prevista no artigo 68. -A do CIRS, desde o ano de 2012, a taxa adicional de solidariedade constitui um adicionamento ao IRS, é da mesma natureza da derrama estadual no IRC. Tal como a derrama estatual, também a taxa de solidariedade é, em rigor, um imposto progressivo em dois escalões, sendo o adicional de 2,5\% aplicado ao rendimento colectável de IRS de mais de 80.000 até 250.000 euros, e de $5 \%$ a taxa aplicável ao rendimento superior a 250.000 euros.

\section{Impacto das tributações autónomas}

As tributações autónomas são uma fonte de receita fiscal, cujo impacto representa mais de $10 \%$ da receita total de IRC

Considerando as anomalias e contradições que se vão avolumando na tributação das empresas, com a crescente desconsideração fiscal de gastos empresariais refletidos na contabilidade e com o constante aumento das tributações autónomas sobre despesas que se revelam necessárias à actividade das empresas, o IRC deixa de ser um imposto sobre o lucro das empresas para se transformar, na prática, em imposto sobre o volume de negócios.

Levando em linha de conta as diversas taxas aplicadas, acrescidas de "taxas de tributação autónoma", agravadas em caso de prejuízo da empresa, e com as tributações avulsas progressivas, bem pode afirmar-se que o IRC deixa de ser um imposto proporcional, para se transformar num anómalo e inconstitucional imposto progressivo

A grande maioria das tributações autónomas que recaem sobre as empresas e que são, na verdade, autênticos impostos especiais, mostram de forma nítida como está anormal o sistema fiscal português. Desde logo, estamos perante verdadeiros impostos - e não taxas, como erroneamente as designou o legislador - uma vez que os sujeitos passivos que os suportam não recebem qualquer contrapartida específica da parte do Estado. E são impostos sobre a despesa, uma vez que o facto tributário que serve de pressuposto da tributação consiste num gasto efetuado pela empresa. Anormalidade que se manifesta de forma grosseira, no plano legislativo, ao tributar todo e qualquer facto económico, independentemente da sua natureza e sem consideração da capacidade contributiva. Mas a anormalidade 
DOI: $10.46294 /$ ulplr-rdulp.siv la5

resulta agravada, desde logo, da circunstância de as tributações "autónomas", que são impostos especiais sobre a despesa, terem sido integradas nos impostos sobre o rendimento ${ }^{35}$

legislador fiscal, lamentavelmente, persiste em contrariar doutrina há muito tempo consolidada em sede de teoria geral dos impostos. $\bigcirc$ que importa é a obtenção da receita e, se for necessário, logo se designa por taxa um verdadeiro imposto, prática legislativa que viola os princípios constitucionais da legalidade tributária e da capacidade contributiva.

Assiste-se a uma multiplicação de impostos, taxas e contribuições especiais sobre os indivíduos, as famílias e as empresas, em que se mostra juridicamente impossível uma qualquer justificação séria que assente na obtenção de um ganho ou "acréscimo patrimonial" efetivo, ou mesmo de um lucro, como únicos pressupostos que devem servir de base ao imposto sobre o rendimento das pessoas singulares e das pessoas coletivas.

Continuamos com um sistema tributário recheado de incongruências várias, em que o legislador utiliza todos os expedientes para captar receita e, consegue os seus objectivos sempre à custa dos mesmos, sobrecarregando os rendimentos do trabalho e de pensões, agravando a carga fiscal das famílias de médios rendimentos, tornando quase insustentável a gestão séria das pequenas e médias empresas.

\section{Notas Conclusivas:}

Compreende-se que as tributações autónomas tenham surgido para onerar situações de elevado risco de evasão fiscal. Todavia, não é aceitável que, com o passar dos anos, se aumente o elenco de novos factos tributários, se altere a sua natureza jurídica, e se agravem as respectivas taxas.

Do que vem de ser dito, podemos concluir que as tributações autónomas das empresas não cumprem, hoje, a sua função originária de combate à fraude e evasão fiscal, pelo que a sua manutenção só se justifica no plano estritamente financeiro de arrecadação de mais receita pública.

Desconsidera-se, de forma grosseira, toda e qualquer opção de gestão normal das empresas. $\bigcirc$ legislador invade, de modo ilegítimo, a esfera de liberdade de gestão empresarial, ao condicionar e sancionar as opções dos órgãos sociais das empresas.

Esta é uma solução em manifesta contradição com o impulso que deve ser dado à racionalidade e competitividade empresarial, em tempos de globalização económica.

Em mercados globais as empresas precisam de criatividade, de inovação e esta não deve ser sancionada.

As empresas precisam de um sistema fiscal mais amigo do investimento, o que só será possível se o sistema fiscal for revisto, de forma a ganhar em coerência, simplicidade e praticabilidade. 
DOI: 10.46294/ulplr-rdulp.siv 1 a5

\section{Bibliografia}

Basto, José Xavier de. "O Princípio da Tributação do Rendimento Real e a Lei Geral Tributária», Fiscalidade 5, (Lisboa: ISG, 2001)

Beltrame, Pierre. La Fiscalité en France, 6. ${ }^{a}$ ed., (Paris: Hachette, 1998)

Bienvenu, Jean-Jacques e Lambert, Thierry. Droit Fiscal, (Paris: PUF, 1987)

Campos, Diogo Leite de e Campos, Mônica Horta Neves Leite de. Direito Tributário, (Coimbra: Almedina, 2003)

Casado Ollero, Gabriel. «El principio de capacidad y el control constitucional de la imposición indirecta (III). El contenido constitucional de la capacidad económica»,

Civitas. REDF, n. 34 , (1982)

Grosclaude, Jacques e Marchessou, Philippe. Droit Fiscal général, (Paris: Dalloz, 1997) Kerviler, Isabelle de. Droit Comptable Entrepises, (Paris: Económica, 1986)

Manzoni, I. II princípio della Capacità Contributiva nell'Ordinamento Costituzionale Italiano, (Torino, 1965)

Martul-Ortega, P. Yebra. La Justicia Fiscal y el Impuesto sobre la Renta, (Universidad de Santiago de Compostela, 1973)

Nabais, José Casalta. «A Tributação das Empresas pelo Rendimento Real», Boletim de Ciências Económicas, Vol. LXII, (Coimbra: FDUC, 2019)

Introdução ao Direito Fiscal das Empresas, (Coimbra: Almedina, 2013)

Direito Fiscal, 7.a ed., (Coimbra: Almedina, 2012)

Pereira, Manuel Henriques de Freitas. «A Periodização do lucro tributável», Ciência e Técnica Fiscal, 349 (janeiro-março de 1988)

Ribeiro, J. J. Teixeira. Lições de Finanças Públicas. 5. a ed., (Coimbra: Coimbra Editora, 1995)

Sanches, J. L. Saldanha. Manual de Direito Fiscal, (Coimbra: Coimbra Editora, 2002)

Sousa, Domingos Pereira de. Direito Fiscal e Processo Tributário, (Coimbra: Coimbra Editora, 2013)

Tilbery, Henry. Imposto de Renda - Pessoas Jurídicas, in Ives Gandra da Silva Martins (Coord.), Curso de Direito Tributário, (São Paulo: Editora Saraiva, 1982) 